\title{
Deformations of Frozen Water Drops and Their Frequencies
}

\author{
By Chuji Takahashi \\ Earth Science Laboratory, Saitama University, Urawa, Japan \\ (Manuscript received 10 February 1975, in revised form 5 November 1975)
}

\begin{abstract}
Freezing experiments of freely falling water drops of diameter $45-765 \mu \mathrm{m}$ were made by using a large cloud chamber 14.7 meters in height. Frequent shattering of freezing water drops is observed not only when water drops are nucleated by silver iodide in suspension but also when they are nucleated by collision with ice crystals after attaining thermal equilibrium with the environment. The frequency of shattering depends considerably on the nucleation temperature $(T n)$ and the drop size $(d)$. The frequency of shattering is especially high in the size range $d=75-135 \mu \mathrm{m}$ when water drops are nucleated at temperatures between -14 and $-20^{\circ} \mathrm{C}$. Spikes are formed when water drops are nucleated at temperatures higher than the air temperature $(T a)$ and are scarcely formed when $T n \simeq T a$. In the case of $T a \simeq-27^{\circ} \mathrm{C}$, the frequency of spike formation increases with the rise of the nucleation temperature and the increase of the drop size.
\end{abstract}

\section{Introduction}

Freezing experiments of supercooled water drops have been carried out by many workers in order to clarify whether they shatter frequently as they freeze and eject ice splinters enough to account for the ice crystal multiplication observed in natural clouds. Dye and Hobbs (1968) and Johnson and Hallett (1968) have shown that a water drop about $1 \mathrm{~mm}$ in diameter, which is suspended on a fiber, scarcely shatters when nucleated after attaining thermal equilibrium with the environment. Brownscombe and Thorndike (1968), Hobbs and Alkezweeny (1968) and Takahashi and Yamashita (1969 and 1970) have made freezing experiments on freely falling water drops and have observed shattering of water drops.

The present paper describes the shapes of deformed water drops frozen in free fall and shows the conditions under which shattering and spike formation occur frequently.

\section{Apparatus and procedures}

Two series of experiments, Experiment I and Experiment II, were carried out in this study. Since they are same as in the previous paper (Takahashi and Yamashita, 1970), the experi- mental apparatus and procedures will be described only briefly.

A large cloud chamber 14.7 meters in height and $28 \mathrm{~cm}$ in diameter is used. Temperature in the chamber is controlled automatically (from 0 to $-33^{\circ} \mathrm{C}$ ) and kept uniform as shown by Yamashita (1971). After the chamber is filled with a supercooled cloud, water drops are dropped from the top of the chamber through a pin hole made on a polyethylene syringe. The syringes are cooled by ice to produce precooled water drops of $0^{\circ} \mathrm{C}$. In order to cover the wide size range of water drops of $d=45-765 \mu \mathrm{m}$, three syringes with different pin hole sizes are used. Hence, as usual, to cover the wide size range, experiments are made three times, while keeping the nucleation temperature and the air temperature constant.

Supercooled water drops are nucleated as follows:

Experiment I Water drops are nucleated with silver iodide in suspension. The nucleation temperature is measured by suspending water drops between two immiscible oils. Measured nucleation temperature scatters within $\pm 3^{\circ} \mathrm{C}$ from a mean value. The nucleation temperature $(T n)$ in this paper shows the mean value. 


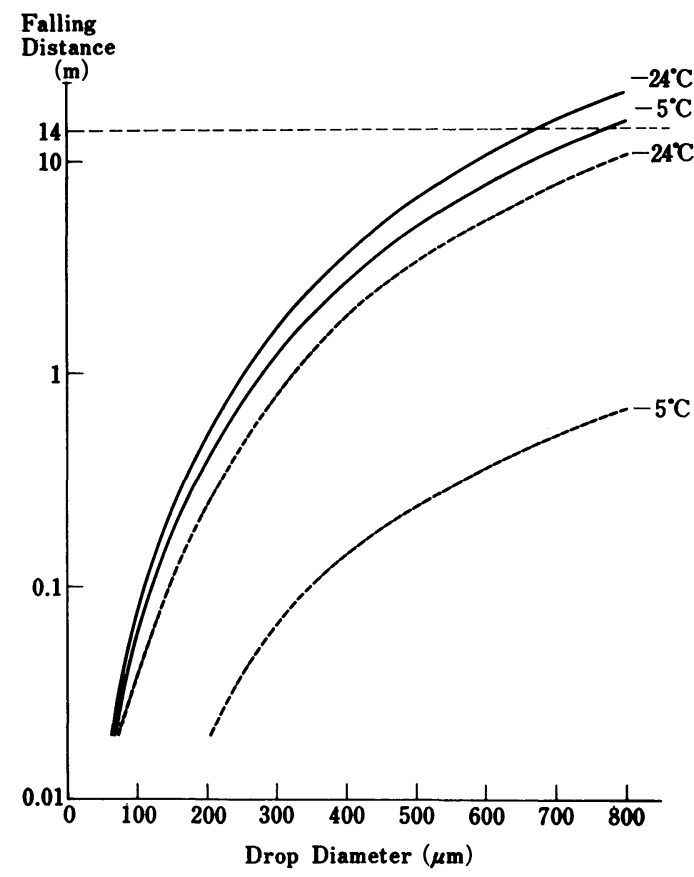

Fig. 1(a) Calculated falling distances of a water drop for its nucleation (dotted lines) and for its complete freezing (solid lines). Initial drop temperature $=0^{\circ} \mathrm{C}, T a=-27$ ${ }^{\circ} \mathrm{C}$ and $\mathrm{Tn}=-5$ or $-24^{\circ} \mathrm{C}$.

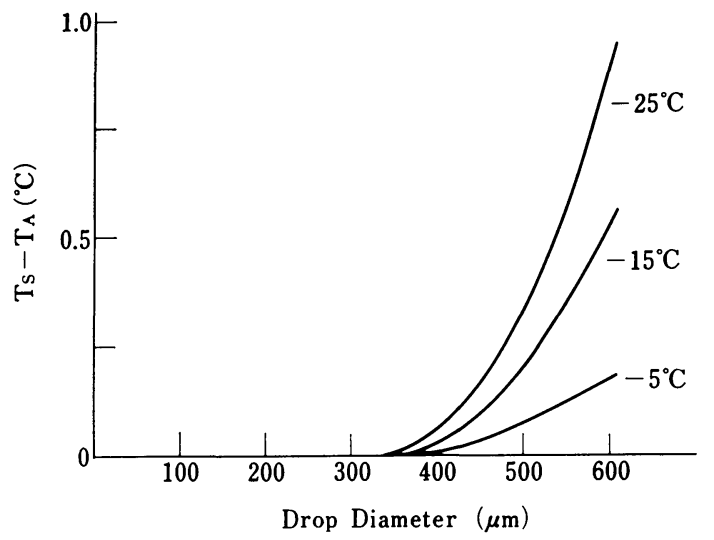

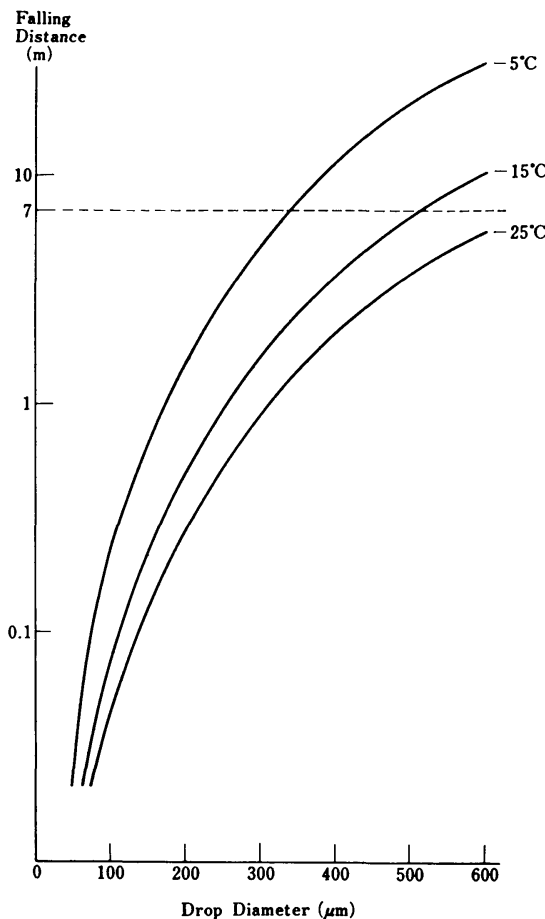

Fig. 1(b) Calculated falling distances from nucleation to complete freezing. The drop is assumed initially to be in free fall attaining thermal equilibrium with the air. $\operatorname{Tn}(=T a)=-5,-15$ or $-25^{\circ} \mathrm{C}$.

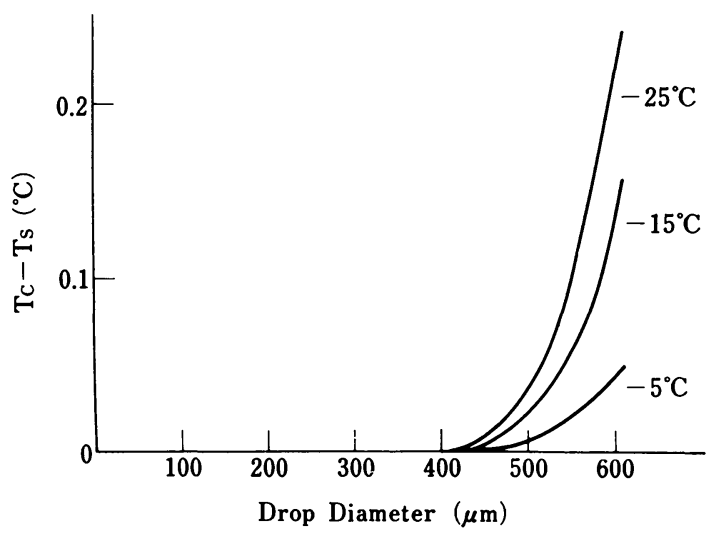

Fig. 2 Calculated temperatures of a water drop when it has fallen 7 meters at a terminal velocity in a cloud chamber of $T a=-5,-15$ or $-25^{\circ} \mathrm{C}$. Initial drop temperature $=0^{\circ} \mathrm{C}$. $T s$, $T c$ and $T a$ are the surface temperature of the drop, the center temperature of the drop and the air temperature, respectively.

Experiment II Water drops are of distilled rod at the level 7 meters below the top of the deionized water, which are cooled down to $-25 \sim$ $-30^{\circ} \mathrm{C}$. They are nucleated by collision with ice cloud chamber. Collided ice crystals are from crystals produced by introducing a cold metal 10 to $20 \mu \mathrm{m}$ in size. 


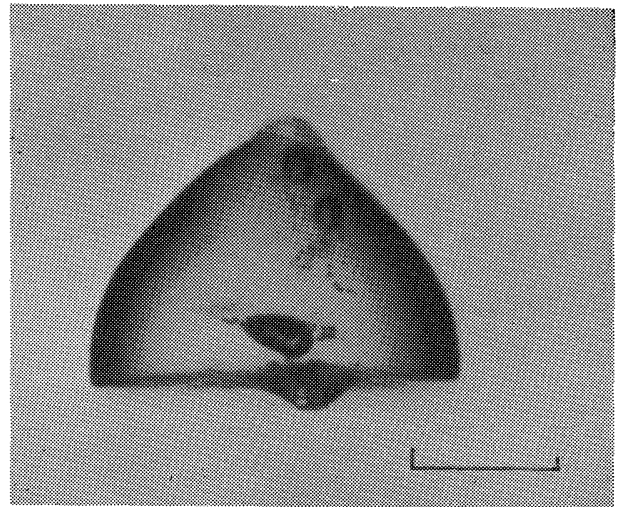

(a)

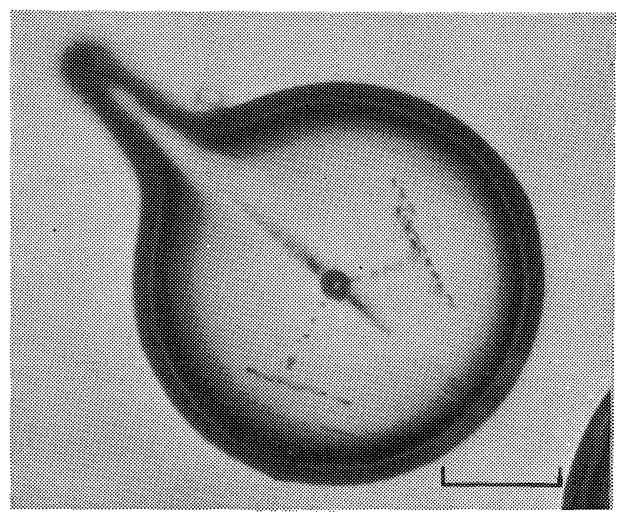

(c)

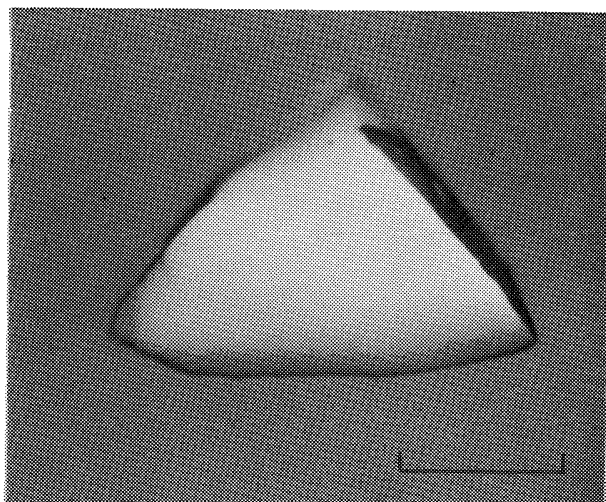

(b)

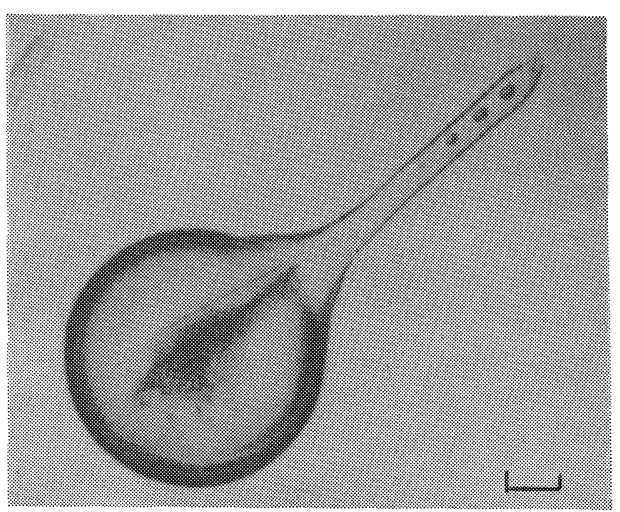

(d)

(a) a shattered fragment with a bulge $T n \simeq-15^{\circ} \mathrm{C}, T a=-24^{\circ} \mathrm{C}$.

(b) a small broken piece $T n \simeq-26^{\circ} \mathrm{C}, T a=-29^{\circ} \mathrm{C}$.

(c) a spike $T n \simeq-6^{\circ} \mathrm{C}, T a=-9^{\circ} \mathrm{C}$.

(d) a long spike $T n \simeq-7^{\circ} \mathrm{C}, T a=-18^{\circ} \mathrm{C}$.

All the water drops freeze completely in free fall. They are collected in the precooled silicone oil of 10,000 centi-stokes and covered with other mineral oil to prevent evaporation. After the drops are carried into a cold room, they are observed under a stereo-microscope. An individual frozen drop is rotated by a glass needle in order to observe three-dimensionally.

In these experiments water drops should freeze completely within 14 meters and 7 meters fall in Experiment I and Experiment II, respectively. The falling distances for the complete freezing of water drops in Experiment I and Experiment II are calculated after Hobbs and Alkezweeny (1968) and Johnson and Hallett (1968), and shown in
Fig. $1 \mathrm{a}$ and Fig. $1 \mathrm{~b}$, respectively. Only water drops, which are inferred to be frozen completely in free fall, are dropped. The surface and center temperatures of a supercooled water drop are also calculated in Experiment II in order to find out whether a water drop has attained thermal equilibrium prior to nucleation or not. Fig. 2 a and Fig. $2 \mathrm{~b}$ show examples of $T s-T a$ and $T c-T s$ when a water drop has fallen 7 meters ( $T c$ and $T s$ are the center and the surface temperature of a water drop, respectively). These figures indicate that the water drop $(d<500 \mu \mathrm{m})$ has attained thermal equilibrium prior to nucleation by ice crystals in Experiment II. 


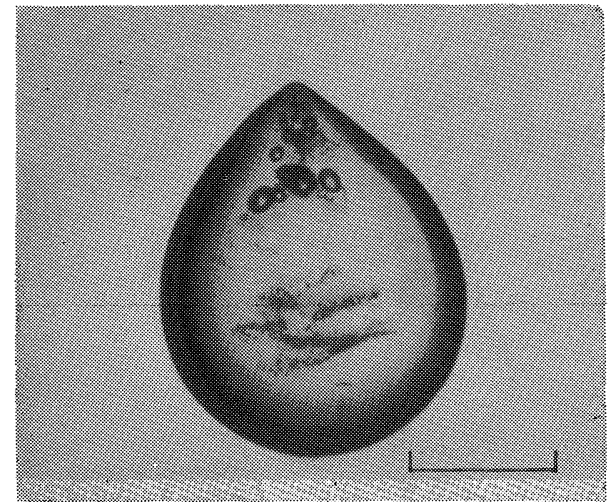

(e)

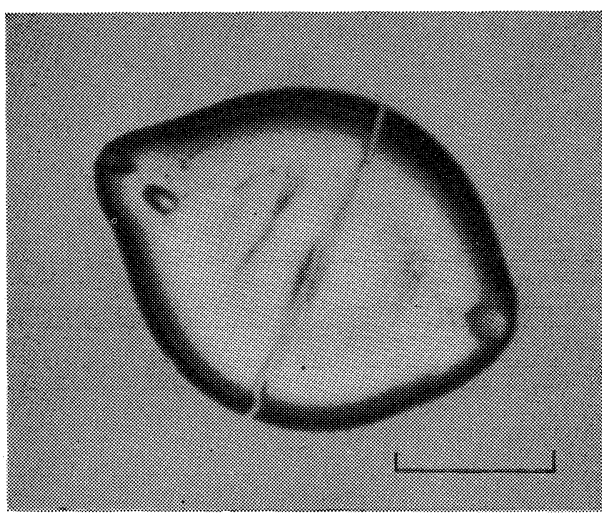

(g)

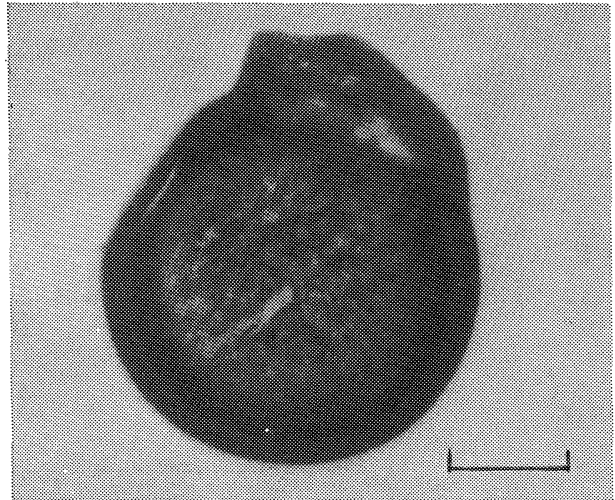

(f)

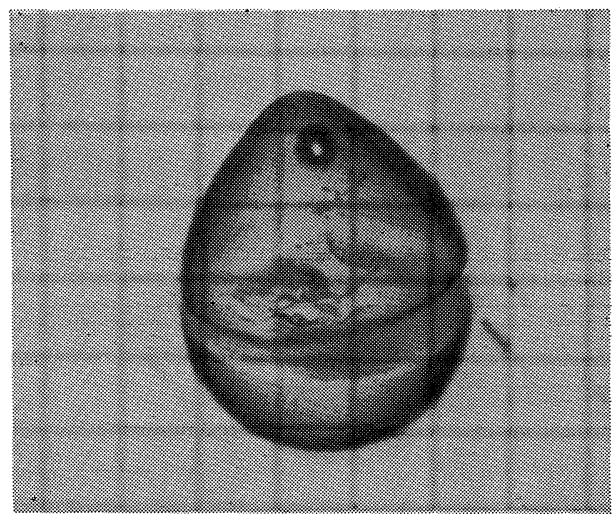

(h)

(e) a bulge $T n \simeq-15^{\circ} \mathrm{C}, T a=-23^{\circ} \mathrm{C}$.

(f) a bulge $\mathrm{Tn} \simeq-24^{\circ} \mathrm{C}, T a=-28^{\circ} \mathrm{C}$.

(g) a cracked drop with two bulges $T n \simeq-7^{\circ} \mathrm{C}, T a=-13^{\circ} \mathrm{C}$.

(h) a split drop with a bulge $T n \simeq-15^{\circ} \mathrm{C}, T a=-21^{\circ} \mathrm{C}$. (grid dimension $=60 \mu \mathrm{m}$ ).

Fig. 3 Shapes of frozen drops (comparison scales $=103 \mu \mathrm{m}$ ).

\section{Types of deformation}

Although the shapes of deformed frozen water drops were of infinite variety, it was possible to classify the deformations into five types in Experiment I as well as in Experiment II. Photographs in Fig. 3, which are from supplementary experiments* to Experiment I, show these types of deformation.

Shattering (Fig. $3 \mathrm{a}$ and b) Those which were inferred to be produced by shattering were hemispherical fragments, almost hemispherical fragments with a spike, almost hemispherical fragments with a bulge, small broken pieces and frozen drops with a defect of a small broken piece. Most of the observed fragments were the former three. For example, of the 206 fragments observed in Experiment I, 87\% were the former three, $5 \%$ were small broken pieces and $8 \%$ were frozen drops with a defect of a small broken piece.

Fractured faces were flat in most cases. However, there were also somewhat rugged faces, flat faces

* The supplementary experiments were made for the purpose of taking photographs of deformed frozen water drops without producing a supercooled cloud, since rimed frozen drops observed in Experiment I and Experiment II were not always appropriate for showing the deformations. 


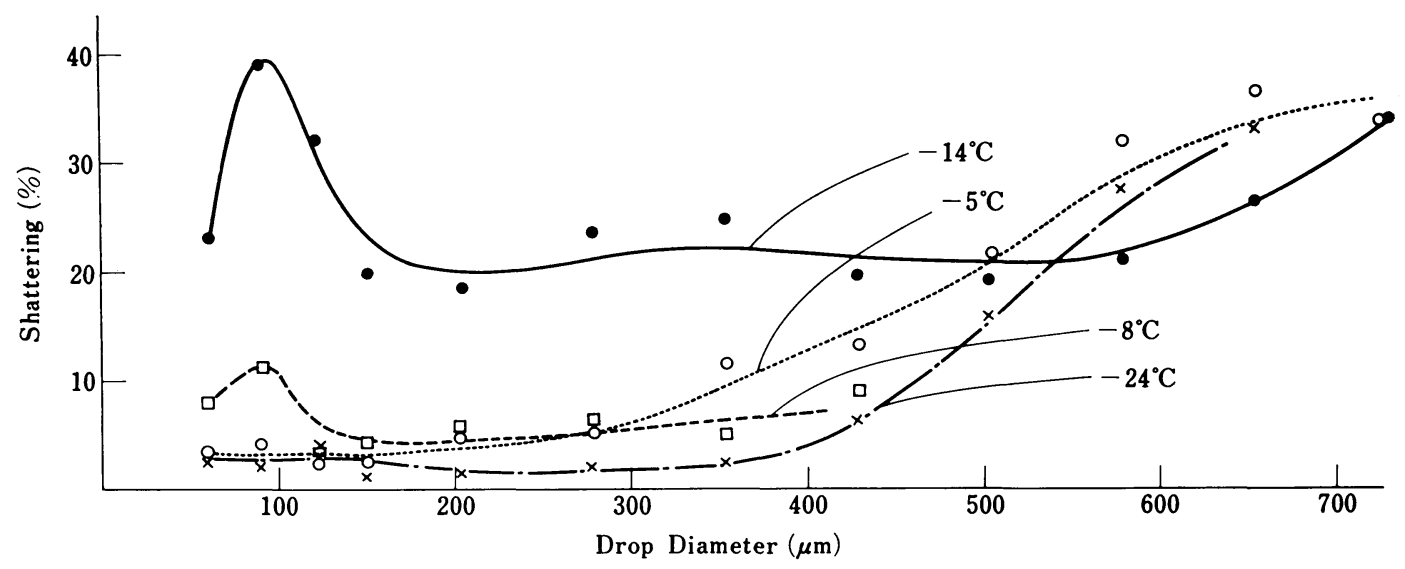

Fig. 4 Frequency of shattering in Experiment I. $T a \simeq-27^{\circ} \mathrm{C}$ (constant) and $T n$ is shown in the figure.

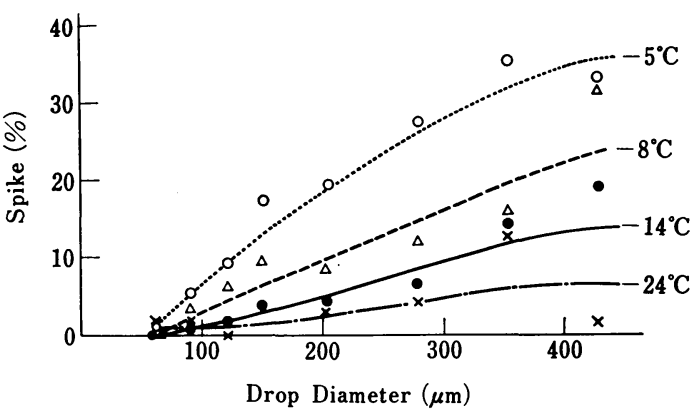

Fig. 5 Frequency of spike formation in Experiment I. $T a \simeq-27^{\circ} \mathrm{C}$ (constant) and $T n$ is shown in the figure.

but slightly swollen at the center (Fig. 3 a) and flat faces but slightly depressed at the center.

Spike (Fig. $3 \mathrm{c}$ and d) In many cases spherical frozen drops had some kinds of protrusion. In the present investigation a protrusion longer than one fourth of the drop diameter was classified as a spike. Usually a spike was neither a cyrindrical nor a conical protrusion but was a rather flat protrusion as if it had been protruded due to a small crack formed on an ice shell.

Air bubbles were found to be arranged from the center of a frozen drop to the tip of a spike.

Bulge (Fig. $3 \mathrm{e}$ and $\mathrm{f}$ ) In the present investigation a protrusion shorter than one fourth of the drop diameter was classified as a bulge. In most cases a frozen drop with a bulge was axially symmetrical, although a bulge which was

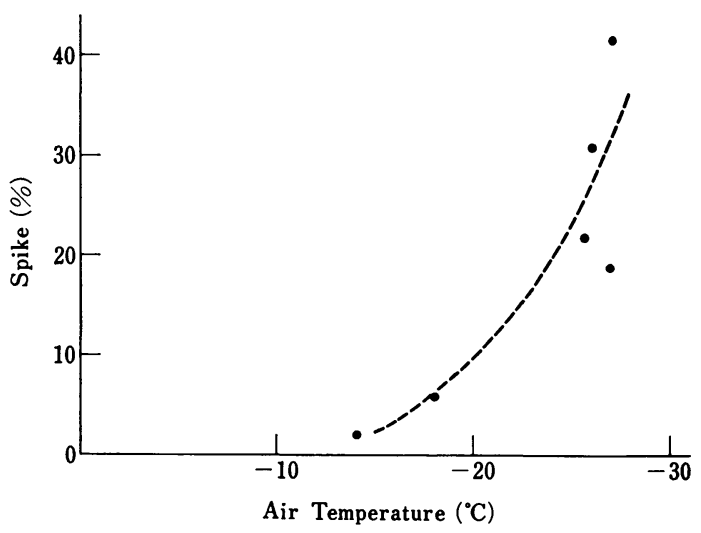

Fig. 6 Frequency of spike formation in Experiment I. $T n \simeq-5^{\circ} \mathrm{C}$ (constant) and $d=250-400$ $\mu \mathrm{m}$.

rather like a spike shown above was also observed. A protrusion like a knob (Fig. $3 \mathrm{f}$ ) was also classified with a bulge.

Many air bubbles were found in a bulge.

Crack (Fig. $3 \mathrm{~g}$ ) A frozen drop had frequently one to a few cracks.

Splitting (Fig. $3 \mathrm{~h}$ )

As was shown in the case of shattering, more than two types of deformation were frequently observed on a frozen drop. For example. about $80 \%$ of almost spherical frozen drops with bulges were found to be cracked or split.

A number of air bubbles were observed in the center of a frozen drop. The number and the size of air bubbles depend on the nucleation temperature rather than the drop size and the air temperature. In Experiment $\mathrm{I}$ in the case of $T n \simeq-24^{\circ} \mathrm{C}$, frozen drops contained numerous 


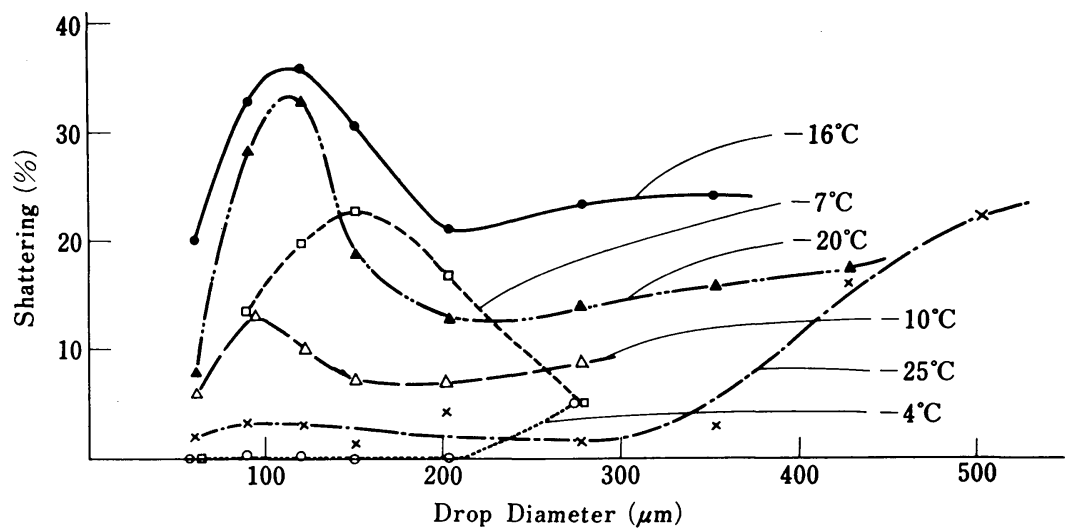

Fig. 7 Frequency of shattering in Experiment II. $\left.T n^{\prime}=T a\right)$ is shown in the figure.

minute air bubbles and looked opaque (see Fig. $3 \mathrm{f}$ ), and in the case of $T n \simeq-5,-8$ and -14 ${ }^{\circ} \mathrm{C}$, frozen drops contained large and not so numerous air bubbles and looked transparent.

\section{Frequency of shattering and frequency of spike formation}

\subsection{Experiment I: Water drops nucleated with silver iodide in suspension.}

4.1.a Experiments were carried out in the cases of $T a \simeq-27^{\circ} \mathrm{C}$ and $T n \simeq-5,-8,-14$ and $-24^{\circ} \mathrm{C}$, and the results are summarized in Fig. 4 and Fig. 5. Frequencies are arranged for every $30 \mu \mathrm{m}$ in the size range $d=45-165 \mu \mathrm{m}$ and for every $75 \mu \mathrm{m}$ in the size range $d=165-765 \mu \mathrm{m}$. Usually, experiments were repeated several times and therefore a plotted value in the figure repre- sents the average of the frequencies, which was obtained by observing about 80 frozen drops. A shattered fragment was counted as half of a frozen drop.

The frequency of shattering was high in the case of $T n \simeq-14^{\circ} \mathrm{C}$ and reached $39 \%$ at the maximum in the size range $d=75-105 \mu \mathrm{m}$. In the cases of $T n \simeq-5$ and $-24^{\circ} \mathrm{C}$, there was a tendency for the frequency of shattering to increase with the increase of the drop size in general. This tendency was clear in the size range $315 \leq d \leq 765 \mu \mathrm{m}$.

The frequency of spike formation increased with the increase of the drop size and with the rise of the nucleation temperature.

4.1.b Experiments were made in the cases of $T n \simeq-5^{\circ} \mathrm{C}$ and $\mathrm{Ta} \simeq-27,-18$ and $-14^{\circ} \mathrm{C}$ in the size range $d=250-400 \mu \mathrm{m}$. One plotted

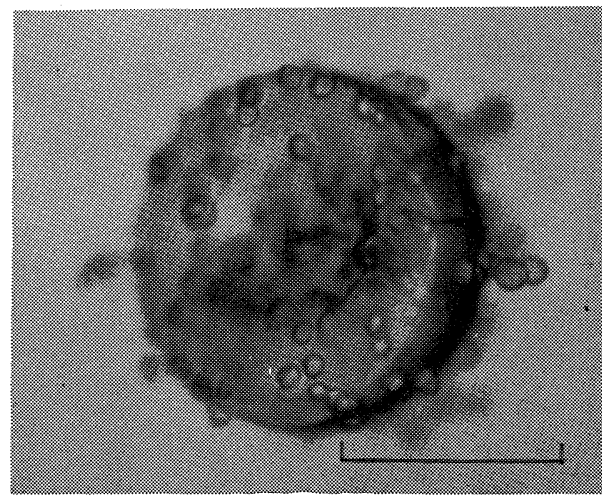

(a)

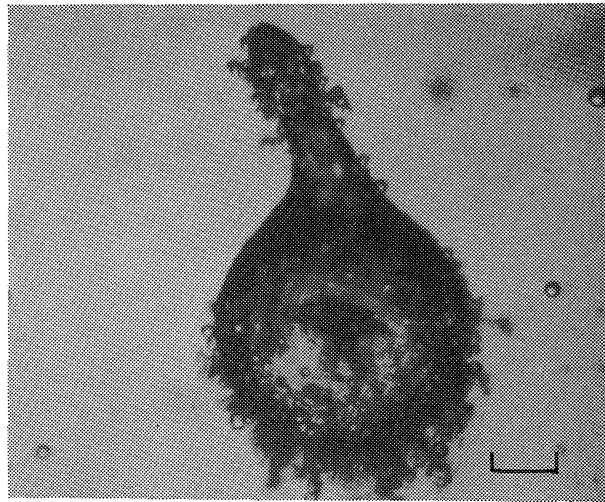

(b)

Fig. 8 Rimed frozen drops (comparison scales $=100 \mu \mathrm{m}$ ).
(a) $\mathrm{Tn} \simeq-19^{\circ} \mathrm{C}, T a=-23^{\circ} \mathrm{C}$.
(b) $\mathrm{Tn} \simeq-16^{\circ} \mathrm{C}, \mathrm{Ta}=-27^{\circ} \mathrm{C}$. 
Bulge
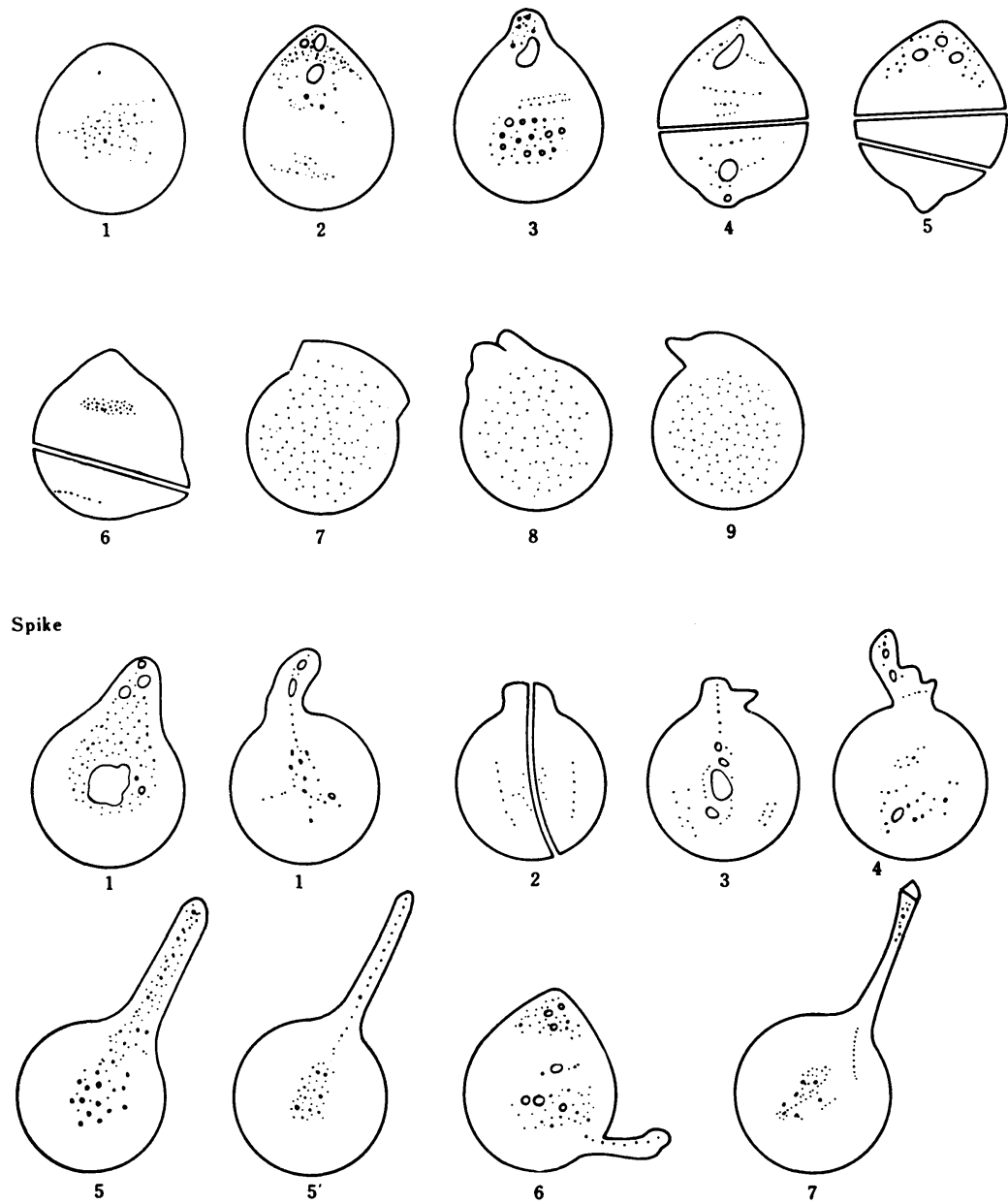

(a)

value was obtained by observing about 50 frozen drops. The frequency of spike formation decreased with the rise of the air temperature and reached a few percent in the case of $T n \simeq-14^{\circ} \mathrm{C}$ (Fig. 6). The frequency of shattering was small.

\subsection{Experiment II: Water drops nucleated by collision with ice crystals}

Experiments were carried out in the cases of $T n(=T a)=-4,-7,-10,-16,-20$ and -24 ${ }^{\circ} \mathrm{C}$, and the results are summarized in Fig. 7 . The frequency of shattering was high in the cases of $T n=-16$ and $-20^{\circ} \mathrm{C}$, reaching the maximum of $37 \%$ and $33 \%$, respectively, in the size range $d=105-135 \mu \mathrm{m}$. It was also high in the case of $T n=-7^{\circ} \mathrm{C}$ and $d=135-165 \mu \mathrm{m}$. In the case of $T n=-10^{\circ} \mathrm{C}$, the frequency was a little high and reached its maximum in the size range $d=75-$ $105 \mu \mathrm{m}$. In the case of $T n=-4^{\circ} \mathrm{C}$ it was zero or a few percent, and in the case of $T n=-25$ ${ }^{\circ} \mathrm{C}$ it was a few percent in the size range $d=$ $45-390 \mu \mathrm{m}$ and increased to about $20 \%$ in the size range $d=390-540 \mu \mathrm{m}$.

The frequency of spike formation was $0 \%$ in the cases of $T n=-4$ and $-7^{\circ} \mathrm{C}$. In the cases of $T n=-10,-16,-20$ and $-25^{\circ} \mathrm{C}$, it was usually less than $5 \%$ and $10 \%$ at most.

\section{Discussions}

In this study, we dropped only water drops which were inferred to be completely frozen in free fall. In fact, since frozen drops were rimed on fractured faces or on tips of spikes when they fell in a supercooled cloud (see Fig. 8), it is 
Crack
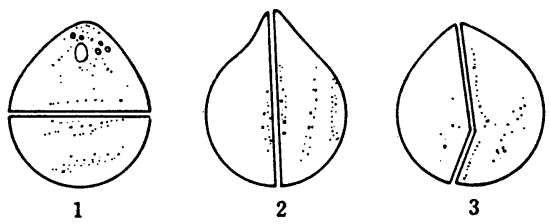

Shattering
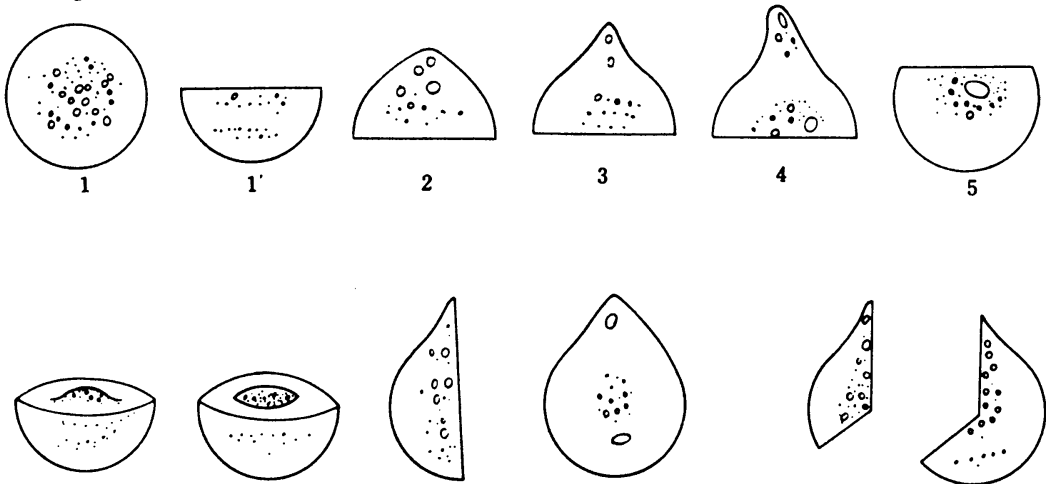

6
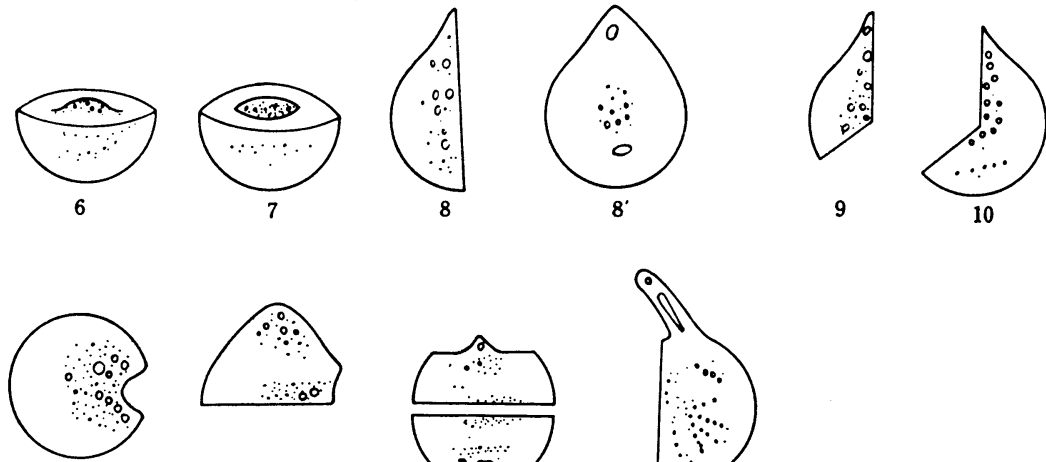

$11^{\prime}$
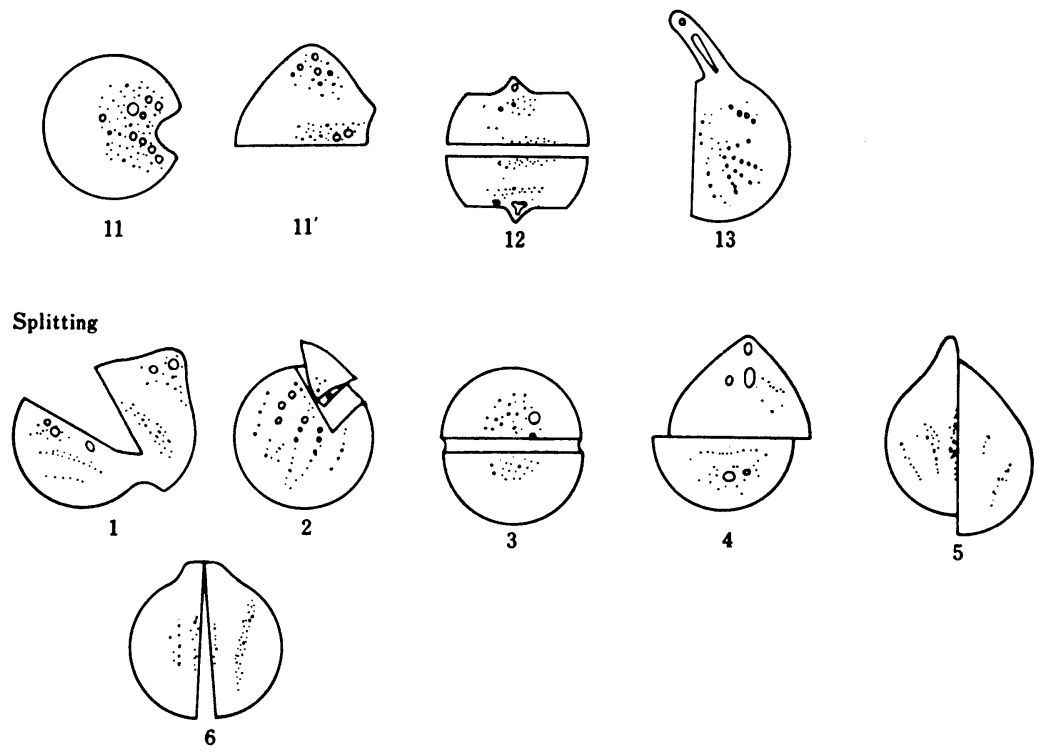

(b)

Fig. 9 Sketches of various deformations. $1^{\prime}, 5^{\prime}, 8^{\prime}$ and $1^{\prime}$ are side views of $1,5,8$ and 11 , respectively. Only two sketches $(6$ and 7 of shattering are drown three-dimensionally)

reasonable to conclude that they had frozen completely in free fall and had not been deformed due to collision with the surface of silicone oil.

\section{Shapes of deformation} Sketches of typical deformed frozen drops are of the ice shell in most cases, although the shown in Fig. 9. Five types of deformation described in section 3 can be classified into a protrusion group (bulge and spike) and a fracture group (crack, split and shattering).

A bulge seems to be formed by the expansion 


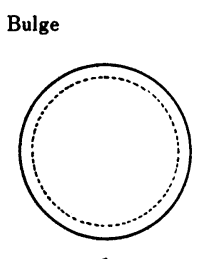

1

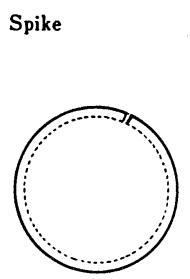

1

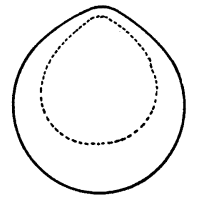

2

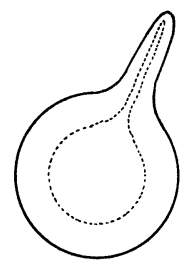

2

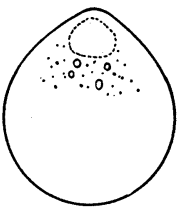

3

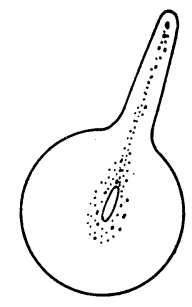

3

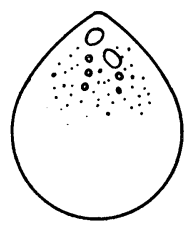

4

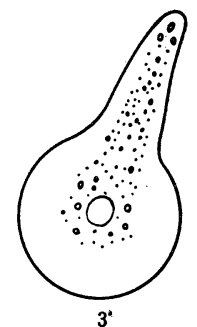

Fig. 10 Formation of a bulge and a spike. Unfrozen water in the ice shell is shown by closing with a dotted line. $3^{\prime}$ is a side view of 3 .

expansion seems to occur not once but two or more times. The air bubbles which are found in a bulge indicate that unfrozen water is left in a bulge until the last stage of freezing as a result of the expansion of the ice shell. A spike, on the other hand, seems to be formed by subsequent freezing of water pushed out of the ice shell through a small crack. These inferences are shown schematically in Fig. 10.

Shattering occurred so as to divide a drop into two almost equal parts in most cases. Shattering, which divides a drop into a small broken piece and a frozen drop with a defect of the small broken piece, also seems to have occurred, because these two kinds of fragments were almost the same in number. However, shattering which divides a drop into three or more than three fragments seems to have scarcely occurred.

A shattered fragment whose fractured face is slightly swollen or depressed roundedly at the center seems to show the presence of small amount of unfrozen water in the shattering.

Effect of the nucleation temperature (Tn) on shattering

The frequency of shattering reached a maximum at $T n \simeq-15^{\circ} \mathrm{C}$, both in Experiment $\mathrm{I}$ and Experiment II. In the case of $T n<-20^{\circ} \mathrm{C}$, the opaque ice shell seems to yield easily to the expansion without shattering, because numerous minute air bubbles make it pliable. When the nucleation temperature is high, the initial transparent ice shell is so thin as to form a bulge or a spike, and the high pressure which causes shattering seems not to be built up.

\section{Effect of the dop size (d) on shattering}

On the whole, the frequency of shattering increased as the drop size increased. However, the frequency of shattering decreased in the cases of $T n \simeq-14 \sim-20^{\circ} \mathrm{C}$ in the size range $d=105-240 \mu \mathrm{m}$ and reached a maximum in the size range $d=75-135 \mu \mathrm{m}$. These effects of the drop size on shattering can not be explained satisfactory from the results of this experiments only.

Effect of the air temperature (Ta) on spike formation

The frequency of spike formation decreased as the air temperature rose in Experiment I. This might be explained by the effect of the cooling rate. Because unfrozen water pushed out of the ice shell spread over the surface of the freezing drop without forming a spike when the cooling rate was small.

The frequency of spike formation was low and usually less than $5 \%$ in Experiment II. Since the frequency of spike formation increased as $\mathrm{Tn}-\mathrm{Ta}$ increased as shown in Experiment I, it 
was low in Experiment II, in which the nucleation temperature $(T n)$ was nearly equal to the air temperature $(T a)$.

\section{Conclusion}

Deformations of the freezing water drop were found to be influenced considerably by the nucleation temperature $(T n)$ and the drop $\operatorname{size}(d)$. Freezing water drops shattered frequently and the frequency exceeded $30 \%$ in the size range $d=75$ $-135 \mu \mathrm{m}$ when water drops were nucleated at temperatures between -14 and $-20^{\circ} \mathrm{C}$. Spikes were formed when water drops were nucleated at temperatures higher than the air temperature, and were scarcely formed when $T n \simeq T a$. In the case of $T a \simeq 27^{\circ} \mathrm{C}$, the frequency increased with the rise of the nucleation temperature and with the increase of the drop size.

In natural clouds, shattering of freezing water drops seems to occur frequently, since conditions there and those in Experiment II are inferred to be almost the same. The relation between the frequent shattering and ice splinter prodution was investigated subsequently and will be reported on elsewhere.

\section{Acknowledgements}

The author wishes to thank Dr. A. Ono of the Meteorological Research Institute for his helpful suggestions and discussions. The author also expresses his thanks to Dr. A. Yamashita of Tokyo University for his invaluable help and encouragement throughout this work, and for letting him use the facilities of Tokyo University. Thanks are also due to Miss K. Nakamura for typewriting.

\section{References}

Brownscombe, J.L., and N.S.C. Thorndike, 1968: Freezing and shattering of water droplets in free fall. Nature, 220, 687-689.

Dye, J.E., and P.V. Hobbs, 1968: The influence of environmental parameters on the freezing and fragmentation of suspended water drops. J. Atmos. Sci., 25, 82-96.

Hobbs, P.V., and A.J. Alkezweeny, 1968: The fragmentation of freezing water droplets in free fall. J. Atmos. Sci., 25, 881-888.

Johnson, D.A., and J. Hallett, 1968: Freezing and shattering of supercooled water drops. Quart. J. Roy. Meteor. Soc., 94, 468-492.

Takahashi, and A. Yamashita, 1969: Deformation and fragmentation of freezing water drops in free fall. J. Meteor. Soc. Japan, 47, 431-436.

$\longrightarrow$, and 1970: Shattering of frozen water drops in a supercooled cloud. $J$. Meteor. Soc. Japan, 48, 373-376.

Yamashita, A., 1971: Skelton ice crystals of nonhexagonal shape grown in free fall. J. Meteor. Soc. Japan, 49, 215-231.

\title{
凍結水滴の変形とその頻度
}

\author{
高 橋 忠 司 \\ 埼玉大学教育学部 地球科学観測実験室
}

高さ $14.7 \mathrm{~m}$ の大型雲箱を使って, 直径 $45 \sim 765 \mu \mathrm{m}$ の自由落下する水滴の凍結実験を行なった. 沃化銀コロイド 溶液から水滴を作る場合と, 蒸留水から水滴を作り, 水滴が周囲と温度平衡に達した後, 水晶と衝突させる場合の二 種類の実験を行なった，水滴が破壊する頻度は水滴の大きさ $(d)$ と凍結温度 $(T n)$ によって著しく変化する. 特に 直径 75 135 $\mu \mathrm{m}$ の水滴が $-14^{\circ} \mathrm{C}$ から $-20^{\circ} \mathrm{C}$ の間で涷結するときにとの頻度は高い. spike は水滴が気温 $(\mathrm{Ta}$ ) より高い温度で涷結するときに生じ，水滴が気温に近い温度で涷結するときには，ほとんぞ生じない，気温が -27 ${ }^{\circ} \mathrm{C}$ のときには，凍結温度が高い活ど，また水滴が大きいほど spike が生ずる頻度は高い。 